\title{
ASSESSMENT OF THE DURATION OF TIME REQUIRED FOR CONVENTIONAL Ti-Ni SINTERING
}

\author{
N. ZHANG*, P. BABAYAN KHOSROVABADI, J.H. LINDENHOVIUS and B.H. KOLSTER \\ Foundation for Advanced Metals Science, Enschede, The Netherlands \\ *S.G.M. P.O. Box 8039, 7550 KA, Hengelo (O), The Netherlands
}

\begin{abstract}
Elemental blends of $\mathrm{Ti}-\mathrm{Ni}$ powder in the TisoNiso ratio were tested by the conventional press and sintered method. The sintering conditions employed were based on solid-state diffusion which resulted in a homogeneous alloy exhibiting the shape-memory effect. An attempt has been made to establish a mathematical model to predict the time required for complete homogenization. The comparison of the calculated values with that of the experimental results revealed consistency.
\end{abstract}

\section{1.-INTRODUCTION}

\begin{abstract}
Powder metallurgy is an alternative method of manufacturing products which is receiving an ever increasing attention with obvious economic benefits. The importance of this approach lies in the possibility of producing novel materials (such as $T \dot{i N i}$ ), in which conventional techniques are cumbersome. Sintering of the elemental blend of $\mathrm{Ti}-\mathrm{Ni}$ powder is an alloying process with the aim to achieve intermetallic compounds of TiNi [1-6]. However the concept of sintering of these powders is rather complicated and is dependent upon the set conditions. If the sintering process is carried out beneath $940^{\circ} \mathrm{C}$ (which is the lowest eutectic point, see fig.1), and with a moderate heating rate, the process will be controlled by solid-state diffusion, otherwise a reactive combustion may prevail [8]. It is the aim of this paper to concentrate and study the solid-state diffusion process in this alloy, and attempt is made to predict the homogenization process by employing a mathematical model.
\end{abstract}

\section{2. -EXPERIMENTAL}

Pure $\mathrm{Ti}$ and $\mathrm{Ni}$ powders having purities of $99.5 \%$ and $99.9 \%$ respectively with a particle size of $-45 \mu \mathrm{m}$ were employed in this study. The powders were blended in a cylindrical mixer and compacted in an uniaxial mode. The relative green densities of the compacts were $80 \%$ of the theoretical value. The compacts prepared had a mean alloy composition of TisoNiso (at\%). Sintering was conducted under Argon atmosphere, by.first pre-vacuuming to $10^{-5}$ Torr, heating up period till the final set temperature was selected as: first heating up to $600^{\circ} \mathrm{C}$ by $20^{\circ} \mathrm{C} / \mathrm{min}$, then $10^{\circ} \mathrm{C} / \mathrm{min}$ to $700^{\circ} \mathrm{C}$ followed by $2{ }^{\circ} \mathrm{C} / \mathrm{min}$ in the range of $750-900^{\circ} \mathrm{C}$. The reason for the low heating rate at the last stage is to prevent combustion. All sintered samples were subjected to SEM and X-ray micro-analysis. To detect the transformation characteristics of the samples, 
a DSC (differential scanning calorimeter) was employed in order to determine $\mathrm{Ms}$, Mr, As, Af and the latent heats. Finally, samples were subjected to mechanical testing, observing their SME (shape-memory effect).

\section{3. -PHENOMENOLOGICAL APPROACH ON THE Ti-Ni SOLID STATE DIFFUSION}

Mass transport during sintering of $\mathrm{Ti}-\mathrm{Ni}$ powders will occur, by mutual fluxes of $\mathrm{Ti}$ and $\mathrm{Ni}$ atoms diffusing oppositely within the distance of two neighbouring particles of different elements, as shown schematically in Fig.2 a. Figs.2 b-e represent the distribution of $\mathrm{Ni}$ molar concentration along the direction of aligning centers of the two connected $\mathrm{Ti}$ and $\mathrm{Ni}$ particles, as the time progresses.

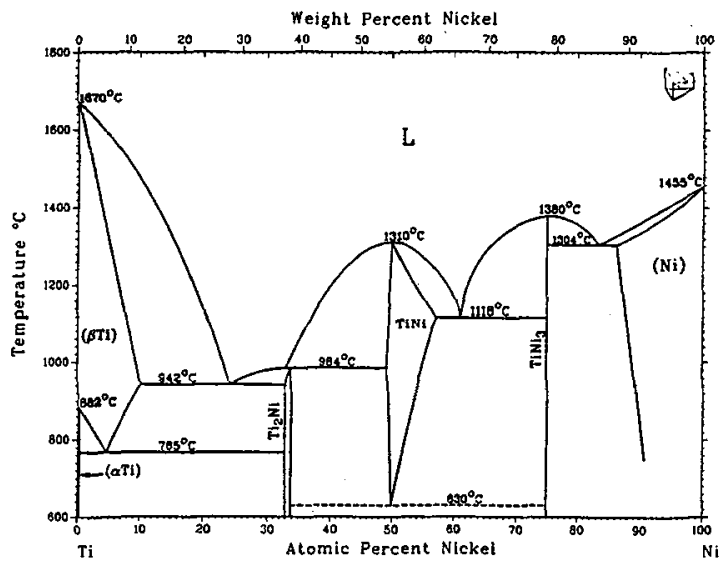

Fig.1 The Ti-Ni binary phase diagram [7]

To predict the homogenization process we refer to Fig.2, in which point $o$ is the position of the original interface between the $\mathrm{Ti}$ and $\mathrm{Ni}$ particle. This reference point is considered to be fixed and does not change with the progressive change of the structure, which is obviously an approximation. $x$ is the distance from the Ti-rich side of the TiNi layer to point $\circ$ and $y$ the distance from the Ni-rich side to point 0 . During sintering, when the TiNi layer grows into its neighbouring $\mathrm{TizNi}$ layer by a step $\Delta x$ in time $\Delta t$, the TiaNi layer contracts by a step $\Delta x^{\prime}$; then the concentration will change from $\mathrm{C}_{1}$ to $\mathrm{C}_{2}$, where $\mathrm{C}_{1}$ is $\mathrm{Ni}$ moles per unit TiaNi volume and $\mathrm{C}_{2}$ the same per unit TiNi volume at the Ti-rich side (close to $\mathrm{TizNi}$ ) of the TiNi layer. It is assumed to be caused by $\mathrm{Ni}$ mass flux, $J$, flowing to the interface of $\mathrm{TiNi} / \mathrm{Ti} \mathrm{Ni}$; thus, we can express

$$
\mathrm{C}_{2} \Delta \mathrm{x}-\mathrm{C}_{1} \Delta \mathrm{x}^{\prime}=\mathrm{C}_{2} \Delta \mathrm{x}-\mathrm{C}_{1} \mathrm{k}_{1} \Delta \mathrm{x} \cong \mathrm{J} \cdot \Delta \mathrm{t}
$$

where $k 1=\Delta x^{\prime} / \Delta x$ is a conversion coefficient due to the different molar volumes of TizNi and TiNi. Basing on Fick's first law, Eq. (1) turns into

or

$$
\begin{aligned}
& \Delta x \cdot\left(C_{2}-k_{1} C_{1}\right) \cong-\bar{D} \cdot \frac{\partial C}{\partial x} \cdot \Delta t \\
& \left(C_{2}-k_{1} C_{1}\right) \cdot d x=-\bar{D} \cdot \frac{\partial C}{\partial x} \cdot d t
\end{aligned}
$$

where $\bar{D}$ is the chemical diffusion coefficient for the TiNi phase and $\frac{a C}{\partial x}$ the concentration gradient in this phase (it should be stressed that $\frac{\partial C}{\partial x}$ is the gradient at the point of boundary of TiNi with TizNi).

The concentration gradient in the TiNi layer has been assumed to be linear, even though this is not an accurate assumption. However, the observed experimental results have indicated linearity [9]. Thus we have

$$
\frac{\partial C}{\partial x}=\frac{C_{2}-C_{3}}{x+y}
$$


In order to conserve the mass balance ratio, $y$ and $x$ must be correlated, e.g., in the case of Fig.3-1 d, Ni moles in TizNi plus those in TiNi3 should be equal to the sum of the $T i$ moles in both phases, which leads to

$$
\begin{aligned}
& (k 2 R-k 1 x) C_{1}+\left(k 4 R^{\prime}-k 3 y\right) C_{4}= \\
& (k 2 R-k 1 x) C_{1}^{\prime}+\left(k 4 R^{\prime}-k 3 y\right) C_{4}^{\prime}
\end{aligned}
$$

where, $R$ and $R^{\prime}$ are radii of the $T i$ and $\mathrm{Ni}$ particles; $\mathrm{C}_{4}, \mathrm{C}_{1}$ and $\mathrm{C}_{4}$ are concentrations of $\mathrm{Ni}$ in the TiNiz phase, $\mathrm{Ti}$ in the TizNi phase and $\mathrm{Ti}$ in $\mathrm{TiNi3}$ in moles per unit volume; $k 2, k 3$ and $k 4$ are molar-volume ratios of $\mathrm{Ti} N \mathrm{Ni}$ to $\mathrm{Ti}$, TiNi3 to TiNi, and TiNi3 to $\mathrm{Ni}$, respectively. If the number of atoms in one $T i$ particle is equal to that in one Ni particle we can relate $R^{\prime}$ with $R$ by $R^{\prime}=k 5 R$, where $k 5$ is a conversion ratio of dimensions. Combining Eq. (3), Eq. (4) and $R^{\prime}=k 5 R$ with Eq. (2) leads to $a$ differential equation

$$
\begin{gathered}
d t=\frac{C_{2}-k_{1} C_{1}}{k_{3} \bar{D}\left(C_{3}-C_{2}\right)}\left[\left(k_{3}+k_{1} \frac{C_{1}-C_{1}}{C_{4}-C_{4}}\right) x+\right. \\
\left.\left(k_{4} k_{5}-k_{2} \frac{C_{1}-C_{1}}{C_{4}-C_{4}^{3}}\right) R\right] d x
\end{gathered}
$$

The fulfillment of homogenization could be judged by the fact that the TiNi layer reaches the center of the original $\mathrm{Ti}$ particle, i.e., $\mathrm{x}=\mathrm{k} 2 \mathrm{R} / \mathrm{k} 1$ in $\mathrm{Fig.2} \mathrm{e}$. Integrating Eq. (5) from 0 to $k 2 R / k 1$ with respect to $x$, we can obtain the time required for complete homogenization

$$
\begin{gathered}
t_{f}=\frac{k_{2}\left(C_{2}-k_{1} C_{1}\right)}{k_{1}\left(C_{3}-C_{2}\right)}\left(\frac{k_{2}}{2 k_{1}}+\frac{k_{4} k_{5}}{k_{3}}-\right. \\
\left.\frac{k_{2}\left(C_{1}-C_{1}\right)}{2 k_{3}\left(C_{4}-C_{4}\right)}\right) \frac{R^{2}}{\bar{D}}
\end{gathered}
$$

It is important to emphasize that the consideration with respect to Eq. (1) constitutes. only the in-flux of $\mathrm{Ni}(\mathrm{J})$, while the out-flux of $\mathrm{Ni}\left(J^{\prime}\right)$ which also flows from the transformed region into the TiaNi layer has been neglected. Otherwise the right hand side of Eq. (1) would have taken the following form of $\left(\mathrm{J}-\mathrm{J}^{\prime}\right) \Delta \mathrm{t}$. However, due to the narrow

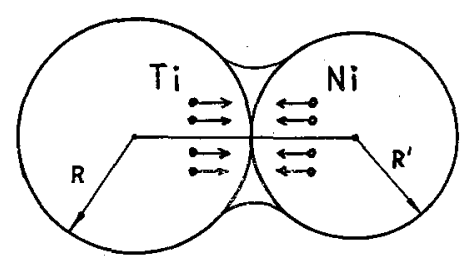

(a)

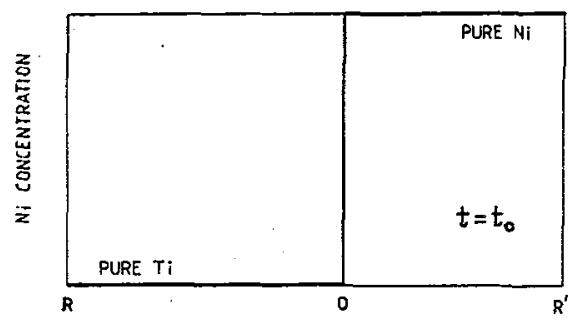

(b)

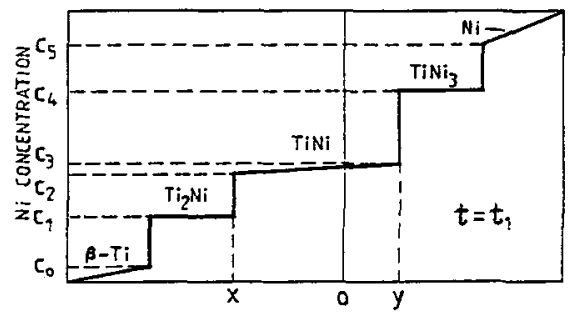

(c)

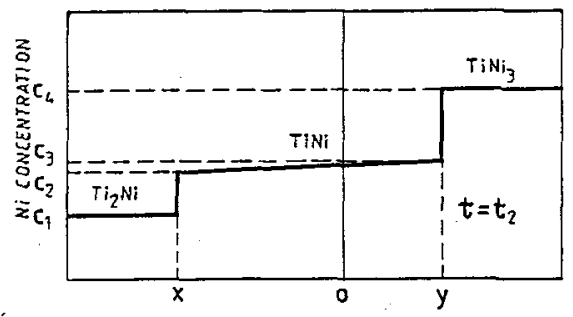

(d)

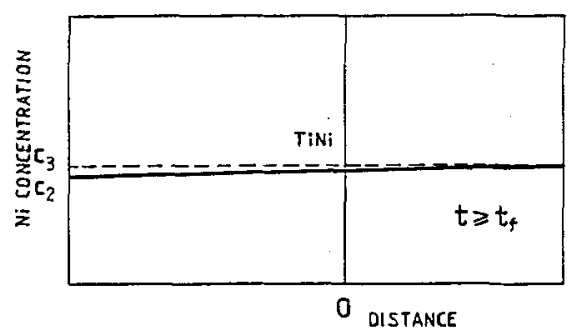

(e)

Fig. 2 Schematic profiles of the solid-state T1-Ni diffusion in one dimension

a) Connection of a TI particle with a NI one

b-e) N1 molar concentration distribution along the align of the centers of the two particles 
homogeneity range of the TiaNi phase and the lack of available data of diffusion in this phase [10], omission of $J$ ' is inevitable. On the other hand, such an omission is acceptable if one notices the fact that

1) J' will always be less than $J$,

2) the existing composition range of the TiaNi phase is rather narrow. Especially after the B-Ti phase vanishes during sintering, see Fig.2d,

a) either, the chemical potential difference (responsible for J') inside $\mathrm{Ti} \mathrm{Ni}$ is small, corresponding to the small composition difference, thus, $J$ ' is negligible;

b) or, if the chemical potential difference is not small and if $\mathrm{J}$ ' is substantial, the TiaNi layer will be saturated immediately due to $J^{\prime}, v i z$, will reach the composition in equilibrium with the TiNi phase. Consequently, the further diffusion should stop completely, $J^{\prime}=0$.

Therefore, it is reasonable to assume the present form of Eq. (1) for the purpose of approximating the time required for homogenization.

\section{4. -EXPERIMENTAL RESULTS}

\section{1.-Structure Analyses}

Sintering was conducted at $900^{\circ} \mathrm{C}$. The molar concentrations at this temperature were determined, by considering the lattice parameters, and their corresponding atomic compositions based on the $\mathrm{Ti}-\mathrm{Ni}$ binary phase diagram. The results are presented below:

$$
\begin{array}{lll}
C_{1}=3.663 \times 10^{-2}, & C_{2}=6.004 \times 10^{-2}, & C_{3}=6.540 \times 10^{-2}, \\
C_{4}=10.598 \times 10^{-2}, & C_{1}=7.326 \times 10^{-2}, & C_{4}=3.533 \times 10^{-2},
\end{array}
$$

in units of $\mathrm{mol} / \mathrm{cm}^{3}$, and

$k_{1}=1.1082, \quad k 2=0.8557, \quad k 3=0.8618, \quad k 4=1.0743, \quad k 5=0.8525$

The chemical diffusion coefficient in the TiNi phase with 50 at\% Ni at $900^{\circ} \mathrm{C}$ was taken as $\overline{\mathrm{D}}=9.5 \times 10^{-10} \mathrm{~cm}^{2} / \mathrm{sec}$, according to Lit. [10]. The particle size of the $\mathrm{Ti}$ and $\mathrm{Ni}$ powders is $45 \mu \mathrm{m}(\mathrm{R}=45 / 2 \mu \mathrm{m})$. By substituting all the above values in Eq. (6), it is now possible to predict the time for total homogenization, which yields $\mathrm{tr}_{\mathrm{r}}=4.9 \mathrm{hr}$.

Fig. 3 a-d reveal the progressive change in microstructure of the samples sintered at $900^{\circ} \mathrm{C}$. As it can be noticed Fig. 3 a represents the starting point where the pure $\mathrm{Ti}$ and $\mathrm{Ni}$ particles are in contact with each other, this clearly corresponds to Fig. 2 b. As the process continues, after an hour (Fig. $3 \mathrm{~b}$ ), the microstructure is revealing formation of intermediate phases, the dark region representing $\beta-\mathrm{Ti}$ and bright clusters being $\mathrm{Ni}$ (plus TiNi3), light grey corresponding to TiNi and dark grey representing Ti2Ni, which relates to Fig. 2 c. Fig. 3 c represents the microstructure after 3 hours of holding time. As it can be noticed only three phases are present, corresponding to the TiNi matrix, TiaNi grey area and TiNi3 light grey area, respectively. Such a structure correlates to Fig.2 d. Finally, Fig.3 d represents the sample after 5 hours of holding time indicating almost a single phase with slight relics of TiNi3 phase. The presence of the second phase is probably due to the non-uniform distribution of the powders during the blending process. Nonetheless the experimental results are in good agreement with that of the predicted values, and justify the application of the model discussed in section 3 . 

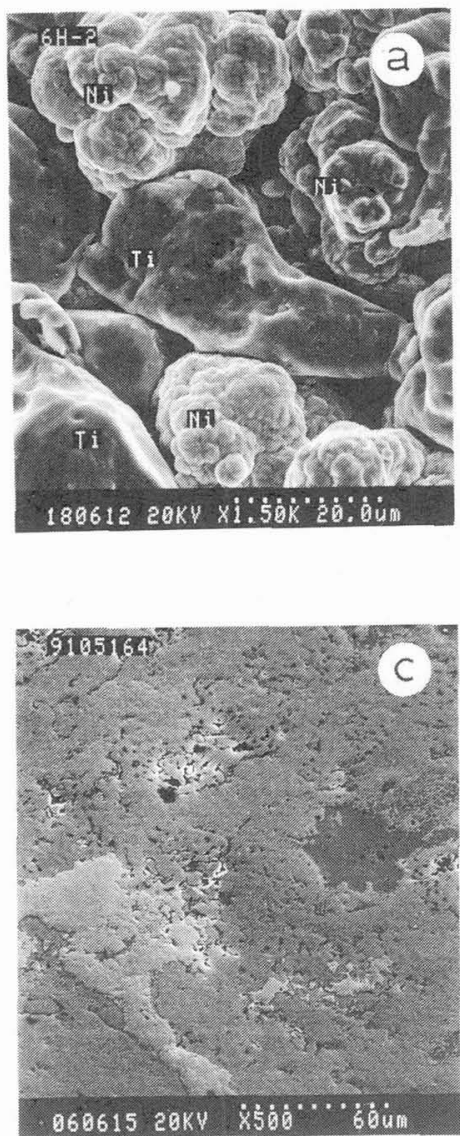
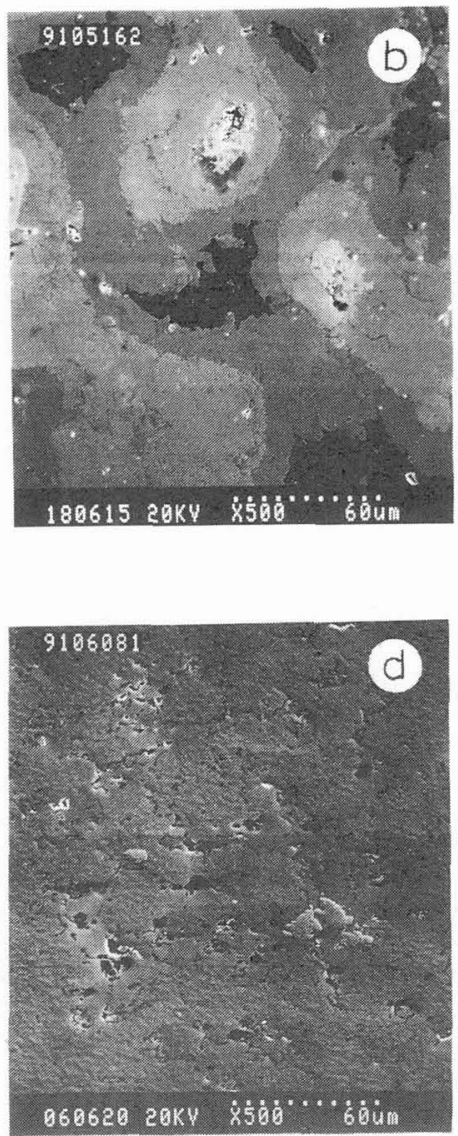

Fig. 3 Microstructures of the TisoNiso samples observed by SEM a) A cross-section of a compact before sintering b-d) sintered at $900^{\circ} \mathrm{C}$ for $1 \mathrm{hr}$, 3hr and $5 \mathrm{hr}$ respectively

\section{2. $-S M E$ of the Sintered TiNi Alloy}

The results of the DSC measurement on the samples sintered for 5 hours at $900^{\circ} \mathrm{C}$, revealed the following values: $M_{s}=68^{\circ} \mathrm{C}, M_{f}=-14^{\circ} \mathrm{C}, A s=44^{\circ} \mathrm{C}$ and $A f=110^{\circ} \mathrm{C}$ (with $\Delta H=24 \mathrm{~mJ} / \mathrm{mg}$ ). Fig. 4 represents such a curve. It is notable that the thermal peak of the martensitic transformation from $M$ s to $M$ is much broader than the peak obtained for the cast alloy, and the reverse transformation exhibits dual peaks, which implies the presence of a transition. The reason for such discrepancies are related to the composition difference existing within the individual grains.

In addition, the same sample sintered at $900^{\circ} \mathrm{C}$ for 5 hours was subjected to tensile testing (Fig.5) by applying a load $\left(\sigma_{a}\right)$ in the martensitic state, and then unloading the sample, where it exhibits a plastic strain of $\varepsilon b$. Keeping the sample fixed in position (within the clamps) and heating the whole sample above the Af temperature, a spontaneous stress oc was recorded due to SME. Finally it was unloaded and the strain of it was corresponding to the new 
value of $\varepsilon d$ (see Fig.5). It is important to emphasize that the data presented are subject to several repeated tests (mechanical training) to achieve a stable SME. From the above results it is found that the recovery force corresponds to $\sigma_{c}=195 \mathrm{MPa}$ and the degree of the recovery, $\gamma=(\varepsilon b-\varepsilon d) / \varepsilon b$, approximates to $67 \%$. Fur thermore, the non linearity of curve $a b$ of Fig. 5 is due to the stress-induced martensitic transformation. Finally, 67\% (not full) recovery is apparently due to existence of porosity in the sintered sample.

\section{5.-CONCLUSIONS}

-Duration of time (tf) for complete homogenization of $\mathrm{Ti}-\mathrm{Ni}$ (having equal particle size) is parabolic with respect to the powder size, i.e, $t_{f}=k \cdot R^{2}$, where $k$ is a proportionality factor.

-According to calculated results based on the chemical diffusion coefficient of the TiNi compound, sintering of the $45 \mu \mathrm{m}$ elemental powders at $900^{\circ} \mathrm{C}$ requires $5 \mathrm{hr}$ to achieve a homogenized TiNì alloy.

-The experimental results indicate similar duration for complete homogenization. The prepared TiNi alloy exhibits the shape-memory effect.

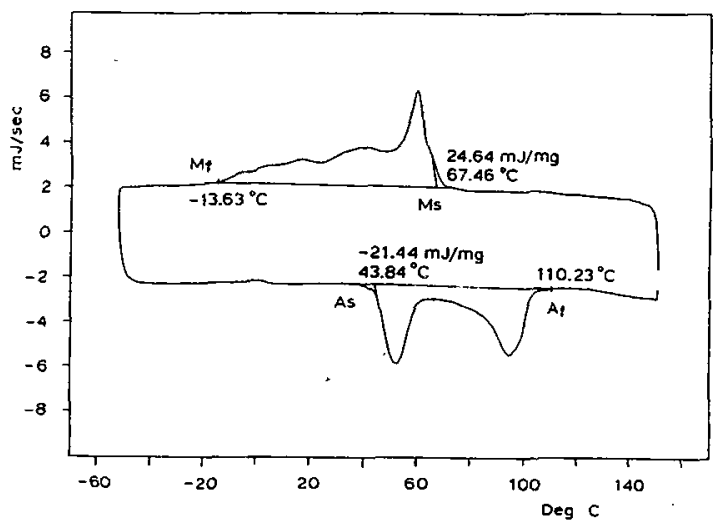

Fig.4 Thermal-analysis curve of the TisoNiso alloy sintered at $900^{\circ} \mathrm{C}$ for $5 \mathrm{hr}$

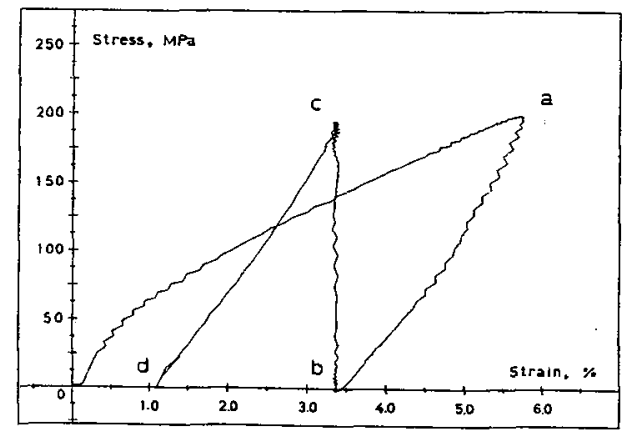

Fig.5 Stress-strain characteristics of the sintered TisoNiso alloy on SME tensile testing

\section{REFERENCES}

[1] G. I.Aksenov, I.A.Drozdov, A.M.Sorokin, D.B.Chernov and Yu. A. Atyakshev. Sov.Powder. Metall.Met.Ceram., Vol.20(1981), P. 340.

[2] K.Funami, Y.Sekiguchi and H.Funakubo, J.Jap. Inst.Metals, Vo1.48, No. $11(1984)$, P. 1113.

[3] M. Igharo and J.V.Wood, Powder Metal1., Vol.28, No.3(1985), P. 131.

[4] R.M.Andrews-Koryta and W.N.Weins, Proc. 25th Annual Conf. Metallurgists, (1986), P.283.

[5] D.G.Morris and M.A.Morris, Mat.Sci.Engin., A110(1989), P. 139.

[6] H.Kuroki, M.Nishio and C.Matsumoto, J.Jpn.Soc.Powder Metall., Vol.36, No.6(1989), P.701.

[7] "Binary Alloy Phase Diagrams", Vol.2, P.1768, ASM, Metals Park, Ohio44073.

[8] H.C.Yi and J.J.Moore, Scripta Metall., Vol.22, (1988), P. 1889.

[9] G.F.Bastin and G.D.Rieck, Metal1.Trans., Vol.5, (1974), P.1817.

[10] G.F.Bastin and G.D.Rieck, Metall.Trans., Vol.5, (1974), P.1828. 